\title{
Click chemistry on NiO photocathode to post-functionalize a diketopyrrolopyrrole sensitizer by naphthalene diimide electron acceptor
}

Yousra Bentounsi, ${ }^{a}$ Konstantinos Seintis, ${ }^{b}$ Stéphane Diring, ${ }^{a}$ Eric Vauthey ${ }^{* b}$ Fabrice Odobel $^{* a}$

${ }^{a}$ Université de Nantes, CNRS, CEISAM UMR 6230, F-44000 Nantes, France. E-mail: Fabrice.Odobel@univ-nantes.fr

Department of Physical Chemistry, University of Geneva, 30 Quai Ernest-Ansermet, CH-1211 Geneva, Switzerland.E-mail: Eric.Vauthey@unige.ch

\begin{abstract}
:
This study addresses a practical aspect of hybrid dye-sensitized photoelectrochemical cells by exploring a simple method to prepare multicomponent systems. Building on a previously reported methodology based on a copper-free click chemistry dipolar cycloaddition of azide with activated alkyne, a naphthalene diimide (NDI) derivative substituted with two propiolic esters was clicked on a $\mathrm{NiO}$ photocathode already coated with a diketopyrrolopyrrole (DPP) dye bearing two azido groups. A detailed photophysical study by transient absorption spectroscopy demonstrates that optical excitation of DPP dye leads to an effective electron transfer chain from the NiO valence band to the NDI passing via the DPP dye, resulting to a long-lived charge-separated state (hole in NiO/NDI radical anion) of $170 \mu$ s. p-type dye-sensitized solar cells were also fabricated with the above molecular components and confirm the occurrence of the electron transfer as the performances of the solar cells were improved in terms of Voc and Jsc compared to the DPP dye lacking the NDI unit. The above clicked system was also compared to a covalently linked DPP-NDI dyad, whose performances are $30 \%$ superior to the clicked system probably due to longer mean distance between the NiO surface and the NDI with the dyad. This finding paves the way for the design of multicomponent hybrid dyesensitized photoelectrochemical cells by chemistry on the electrode.
\end{abstract}




\section{Introduction}

Hybrid nanomaterials consisting of a nanocrystalline metal oxide film whose surface area is coated with a molecular system are the key components of dye-sensitized solar cells (DSSCs), ${ }^{1}$ dye-sensitized photoelectrosynthetic cells (DSPECs) ${ }^{2,3,4}$ and even other electronic devices. ${ }^{5,6}$ So far, many studies on dye-sensitized photoelectrochemical cells have mostly focused on the design of more efficient sensitizers ${ }^{1,7}$ or catalysts, ${ }^{8,9}$ but they are very few works devoted to the development of versatile and powerful fabrication techniques to assemble several molecular components on the surface of mesoporous metal oxide films. On one hand, copper-catalyzed click chemistry between an azide and a terminal alkyne is a classical strategy to functionalize surfaces. ${ }^{10,11}$ Notable examples of this approach are the modification of flat surfaces of gold ${ }^{12}$ and silica, ${ }^{13}$ of spherical nanoparticles, ${ }^{14}$ and even mesoporous metal oxide layers. ${ }^{15,16,17,18}$ Except for the recent elegant works of Dinolfo and coworkers on flat ITO substrates, ${ }^{19,}{ }^{20}$ surface post-functionalization is, however, often limited to the immobilization of a single molecular component via a simple alkyl chain terminated by azido or alkyne group and grafted on the surface via a carboxylic or alkoxysilane anchoring group. On the other hand, it is well accepted that molecular complexity is a prerequisite to achieve elaborated functions. In this context, preformed bi-component molecular systems, such as "dye-catalyst" systems for DSPECs, have been prepared prior immobilization on the surface, but they require tedious, multistep procedures and complex chromatographic separations. ${ }^{3,4,21,22,23}$ A bottom-up approach that permits the straightforward functionalization of a porous film by the successive grafting of different molecular components onto each other would be extremely useful to achieve complex functionalities such as highly active photocatalytic systems and even beyond, but they are rare and particularly on mesoporous electrodes. Meyer and co-workers have reported two interesting strategies toward this goal. One is based on the reductive electro co-polymerization of vinyl groups born by the dye and an oxidation catalyst ${ }^{24,25,26}$ and the other method makes use of phosphonate chemistry between the free phosphonic acid groups on a dye and a catalyst which are assembled via a zirconium(IV) cation. ${ }^{27}$ In the same vein, more recently Tian and Hammarström have used the amide-coupling reaction to attach catalysts on a silatrane-decorated $\mathrm{NiO}$ photocathode. ${ }^{28,29}$ Building on an innovative copper-free click chemistry strategy, ${ }^{30}$ which proved very efficient to stabilize the dye from the desorption from the electrode, we investigate herein the possibility to implement this strategy to post-functionalize the photoelectrode with an active component to fabricate a photoactive hybrid system in view of obtaining a more elaborate property (Scheme 1). More specifically, we have explored the opportunity to introduction of a naphthalene diimide (NDI) electron acceptor by click chemistry on the already chemisorbed DPP layer on NiO electrode in order slow down the usually fast geminate charge recombination reaction. 


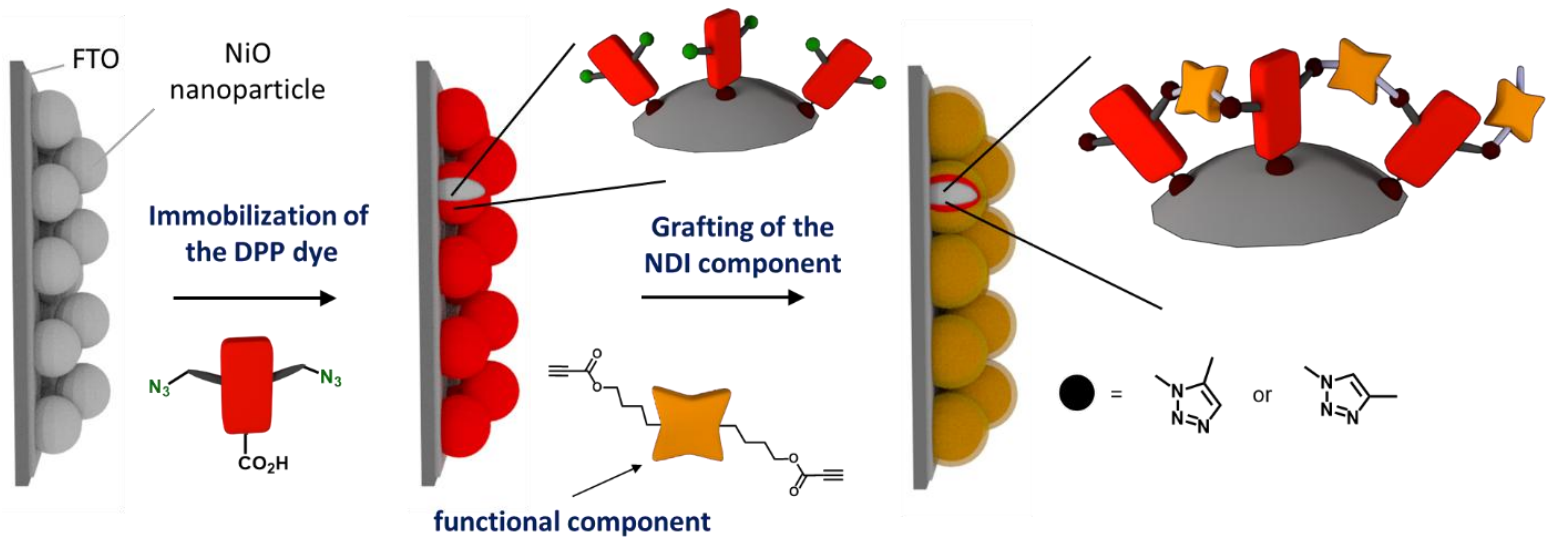

Scheme 1. Schematic representation of the click chemistry reaction directly conducted on NiO nanocrystalline electrode with symbolic representation of the DPP dye (red) and NDI electron acceptor (yellow star).

It is well accepted that charge recombination is one of the major causes of the low performances of p-DSSCs and the introduction of a secondary electron acceptor to the sensitizer is an effective strategy to overcome this problem. ${ }^{31,32,33,34}$ Moreover, in p-DSPEC it is crucial to efficiently shuttle several reducing equivalents produced on the dyes to activate the catalysts prior the catalytic event. Our objective in this study was, therefore, to explore if the post-functionalization of the DPP dye by copper-free click reaction with NDI could be compatible with the effective electron transfer from DPP to this secondary electron acceptor. In case of success, this would pave the way to the straightforward incorporation of many reduction catalysts for the fabrication of DSPECs. Toward this end, we have prepared the new NDI, which was clicked to the DPP dye after its chemisorption on $\mathrm{NiO}$ electrode (Chart and Scheme 1). The previously reported dyad DPP-NDI ${ }^{34}$ was also studied for comparison purposes. The photophysical study by transient absorption spectroscopy and the photovoltaic measurements clearly evidence that the electron-transfer chain from the valence band of NiO to the NDI via the photoexcited DPP effectively occurred in the clicked assembly. 


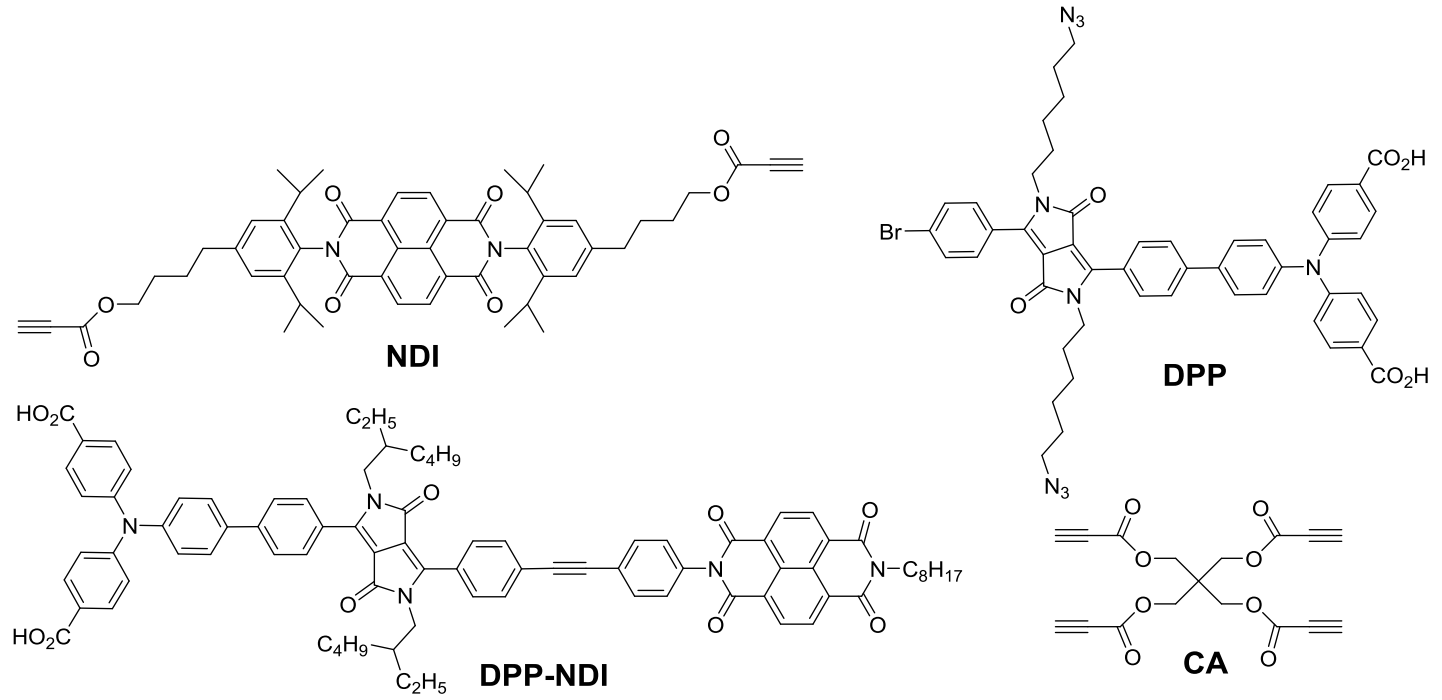

Chart. Structures of the components investigated in this work.

\section{Fabrication of the assembly on mesoporous electrode}

The synthetic route of the NDI is illustrated on Scheme 2. In brief, 4-iodo-2,6-diisopropylaniline $\mathbf{1}$ was coupled to 3-butyn-1-ol according to a Sonogashira cross-coupling reaction and the triple bond was reduced quantitatively with hydrogen on palladium on charcoal to afford the aniline derivative 3 . The latter aniline $\mathbf{3}$ was condensed in refluxed acetic acid with naphthalenetetracarboxylic dianhydride to afford the naphthalene diimide 4 in which the alcohol groups were esterified into acetate. This was not an issue, since the acetate groups can be subsequently trans-esterified by 3-(trimethylsilyl) propiolic acid in good yield (87\%) in the next step. Finally, the trimethylsilyl (TMS) protecting groups were cleaved by tetrabutylammonium fluoride (TFA) in almost quantitative yield to give NDI.
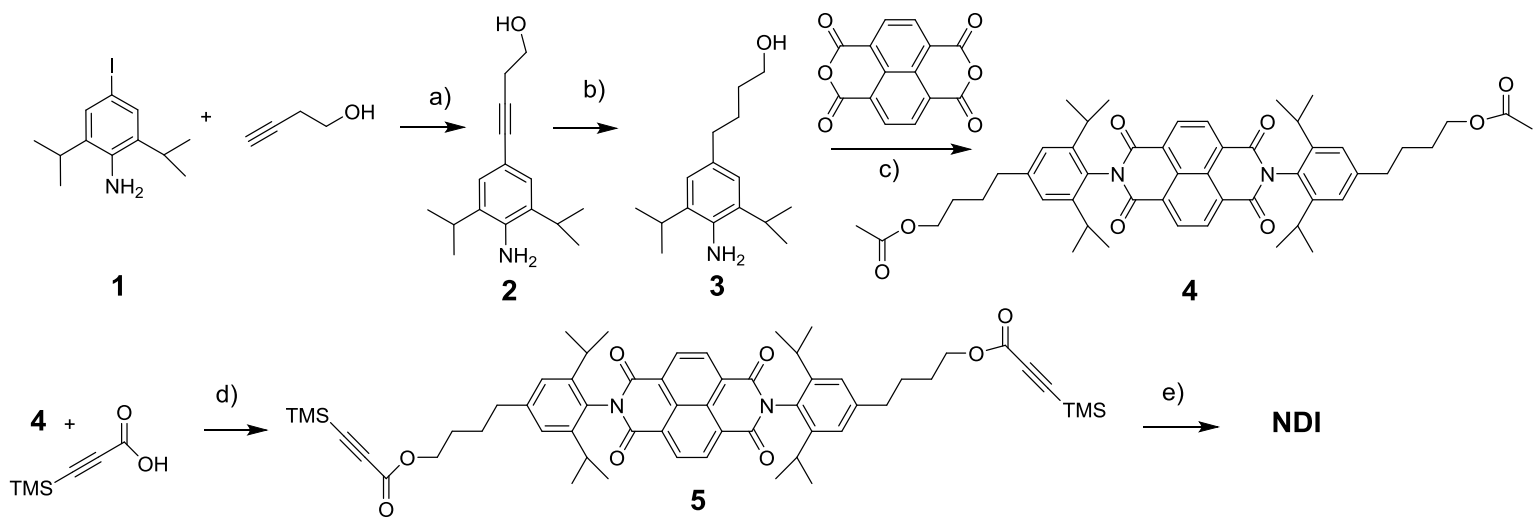

Scheme 2. Synthetic scheme for NDI. Reagents and conditions: a) $\mathrm{Pd}\left(\mathrm{PPh}_{3}\right)_{2} \mathrm{Cl}_{2}, \mathrm{Cul}, \mathrm{Et}_{2} \mathrm{NH} / \mathrm{THF}(1 / 2)$, RT, $12 \mathrm{~h}, 70 \%$; b) $10 \%-\mathrm{Pd} / \mathrm{C}$, AcOEt, RT, 12h, 99\%; c) acetic acid, $120{ }^{\circ} \mathrm{C}, 12 \mathrm{~h}, 54 \%$; d) APTS, benzene, $90^{\circ} \mathrm{C}, 5 \mathrm{~d}, 87 \%$; e) TBAF, acetic acid, THF, RT, 30min, $99 \%$. 
The NDI was connected to the DPP dye already grafted on nanocrystalline NiO electrode by click reaction by a simple heating at $140^{\circ} \mathrm{C}$ for 20 minutes of the $\mathrm{NiO}$ photocathode into an orthodicholorobenzene solution of NDI (see ESI materials for detailed experimental conditions). We have previously demonstrated that these conditions exclusively lead to Huisgen cycloaddition product as schematically shown in Scheme $1 .^{30}$ The reaction was monitored by ATR-IR spectroscopy (Figure 1). The NDI displays characteristic IR bands located around $1717 \mathrm{~cm}^{-1}$ and $1675 \mathrm{~cm}^{-1}$ for asymmetric and symmetric stretching band of carbonyl group on diimide and the also intense $\mathrm{C}-\mathrm{N}-\mathrm{C}$ absorption at $1340 \mathrm{~cm}^{-1} \cdot{ }^{35}$ Moreover, the carbonyl group of propiolate ester is located around 1708 $\mathrm{cm}^{-1}$ and that of the lactam of DPP at $1676 \mathrm{~cm}^{-1} .{ }^{30}$ The ethynyl stretching band at $2118 \mathrm{~cm}^{-1}$ of NDI completely collapsed after heating while that of the azido at $2098 \mathrm{~cm}^{-1}$ has strongly shrunk, evidencing thus that most of these two reacting groups have been consumed during the functionalization process. Interestingly, after click reaction and abundant rinsing of the photocathode, the carbonyl stretching band of diimide groups in NDI and of the propiolate ester around $1710 \mathrm{~cm}^{-1}$ appeared next to that of the lactam groups of DPP at $1670 \mathrm{~cm}^{-1}$ accounting for the covalent attachment of the NDI to the DPP dye (Figure 1).

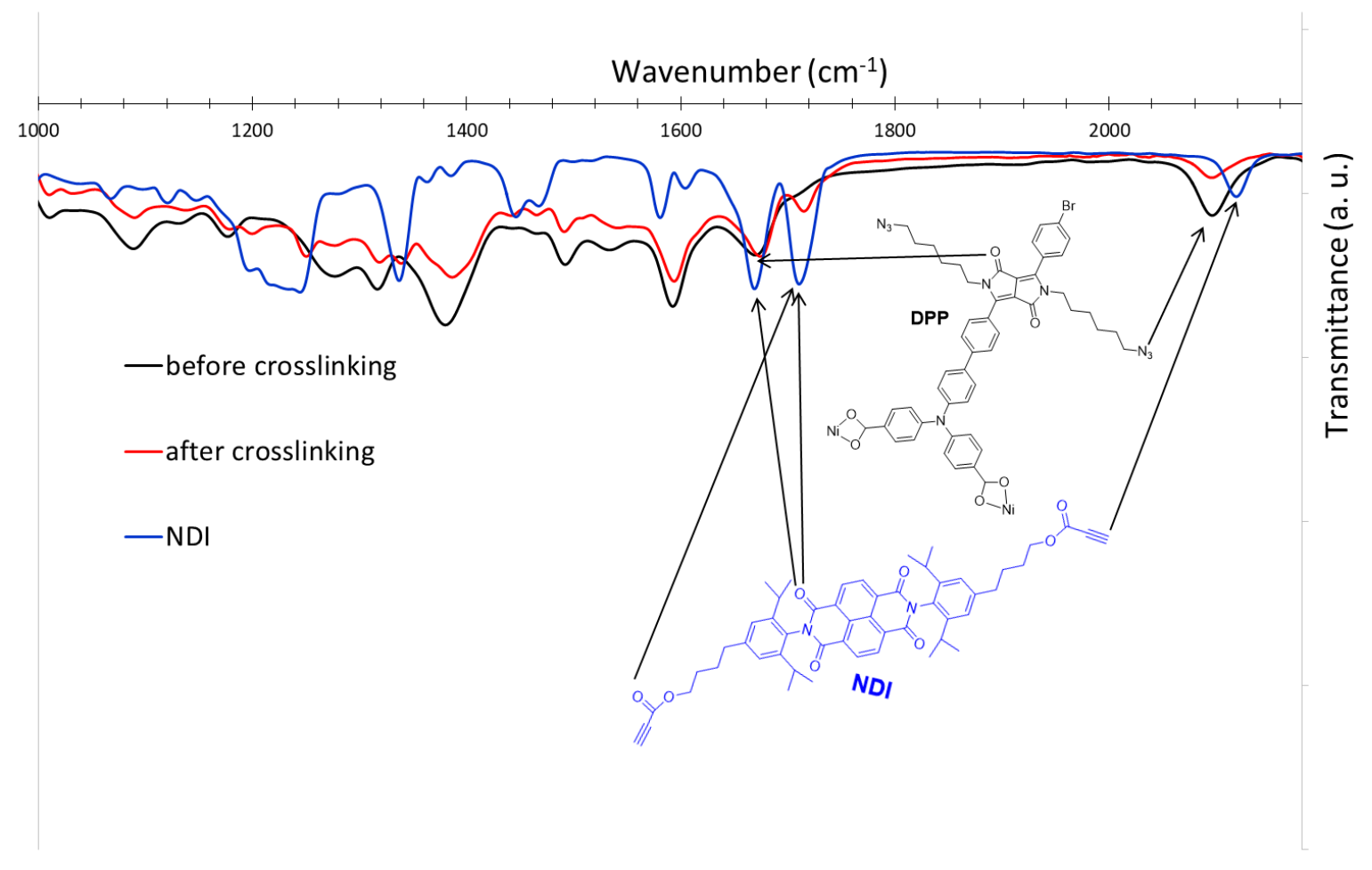

Figure 1. ATR-IR spectra of NDI powder (blue) and of the NiO electrodes coated with DPP before (black) and after click reaction with NDI (red). 
Table 1. Spectroscopic and electrochemical data of the compounds and Gibbs free energy for the hole injection into $\mathrm{NiO}\left(\Delta \mathrm{G}_{\text {hinj }}\right)$ and for the dye regeneration reaction $\left(\Delta \mathrm{G}_{\text {reg }}\right)$ by the cobalt electrolyte.

\begin{tabular}{|c|c|c|c|c|c|c|}
\hline & $\begin{array}{c}\lambda_{\text {abs }} / \varepsilon \\
\left(\mathrm{nm} / \mathrm{M}^{-1} \times \mathrm{cm}^{-1}\right)\end{array}$ & $\begin{array}{c}\mathrm{E}_{00} \\
(\mathrm{eV})^{\mathrm{a}}\end{array}$ & $\begin{array}{c}\mathrm{E}_{\text {Red }}(\mathrm{NDI} / \mathrm{NDI}) \\
(\mathrm{V} \text { vs. SCE })\end{array}$ & $\begin{array}{c}\mathrm{E}_{\text {Red }}\left(\mathrm{DPP} / \mathrm{DPP}^{-}\right) \\
(\mathrm{V} \text { vs. SCE })\end{array}$ & $\begin{array}{c}\Delta \mathrm{G}_{\text {hinj }} \\
(\mathrm{eV})^{\mathrm{b}}\end{array}$ & $\begin{array}{c}\Delta \mathrm{G}_{\text {reg }} \\
(\mathrm{eV})^{\mathrm{c}}\end{array}$ \\
\hline DPP $^{\mathrm{d}}$ & $489\left(2.22 \times 10^{4}\right)$ & 2.33 & - & $-1.20 \mathrm{~V}$ & -0.83 & -1.41 \\
\hline NDI & $\begin{array}{c}362\left(2.54 \times 10^{4}\right) ; \\
382\left(2.82 \times 10^{4}\right)\end{array}$ & - & $-0.52 \mathrm{~V}$ & - & - & - \\
\hline DPP-NDI $^{\mathrm{e}}$ & $\begin{array}{c}380\left(5.08 \times 10^{4}\right) ; \\
492\left(2.20 \times 10^{4}\right)\end{array}$ & 2.29 & $-0.60 \mathrm{~V}$ & $-1.22 \mathrm{~V}$ & -0.77 & -0.81 \\
& & & & & \\
\hline
\end{tabular}

${ }^{a}$ calculated according to the equation: $\mathrm{E}_{00}=1240 / \lambda_{\text {inter, }}$, with $\lambda_{\text {inter }}$ the wavelength at the intersection of the normalized absorption and emission spectra. ${ }^{b}$ Calculated according to the equation: $\Delta G^{\circ}{ }_{\text {inj }}=$

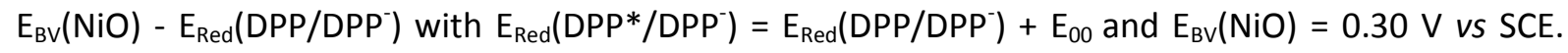

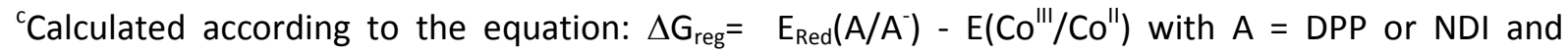

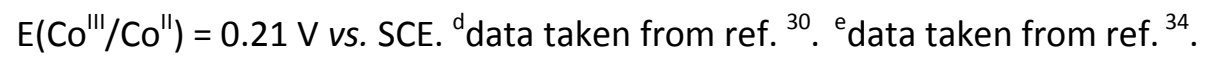

The electronic absorption spectra were also recorded on mesoporous $\mathrm{Al}_{2} \mathrm{O}_{3}$ electrodes, because the transparency of $\mathrm{Al}_{2} \mathrm{O}_{3}$ films is much higher than that of $\mathrm{NiO}$ films. ${ }^{36,37}$ After the click reaction, the $\pi$ $\pi^{*}$ transition of NDI is clearly discernible in the spectrum as a shoulder at $380 \mathrm{~nm}$ and its relative intensity matches very well with that of the DPP-NDI dyad (Figure 2). The extinction coefficient of the DPP in both compounds (DPP and DPP-NDI) being very similar, the comparison of the absorption spectra on mesoporous $\mathrm{Al}_{2} \mathrm{O}_{3}$ of DPP clicked with NDI with that of the DPP-NDI dyad qualitatively indicates that there is be about one NDI unit per DPP dye after the click reaction. The absorption band of DPP chromophore (around $500 \mathrm{~m}$ ) is slightly red shifted in DPP-NDI compared to that of DPP because of the increased $\pi$-conjugation upon connection of NDI via the triple bond. ${ }^{34}$ 


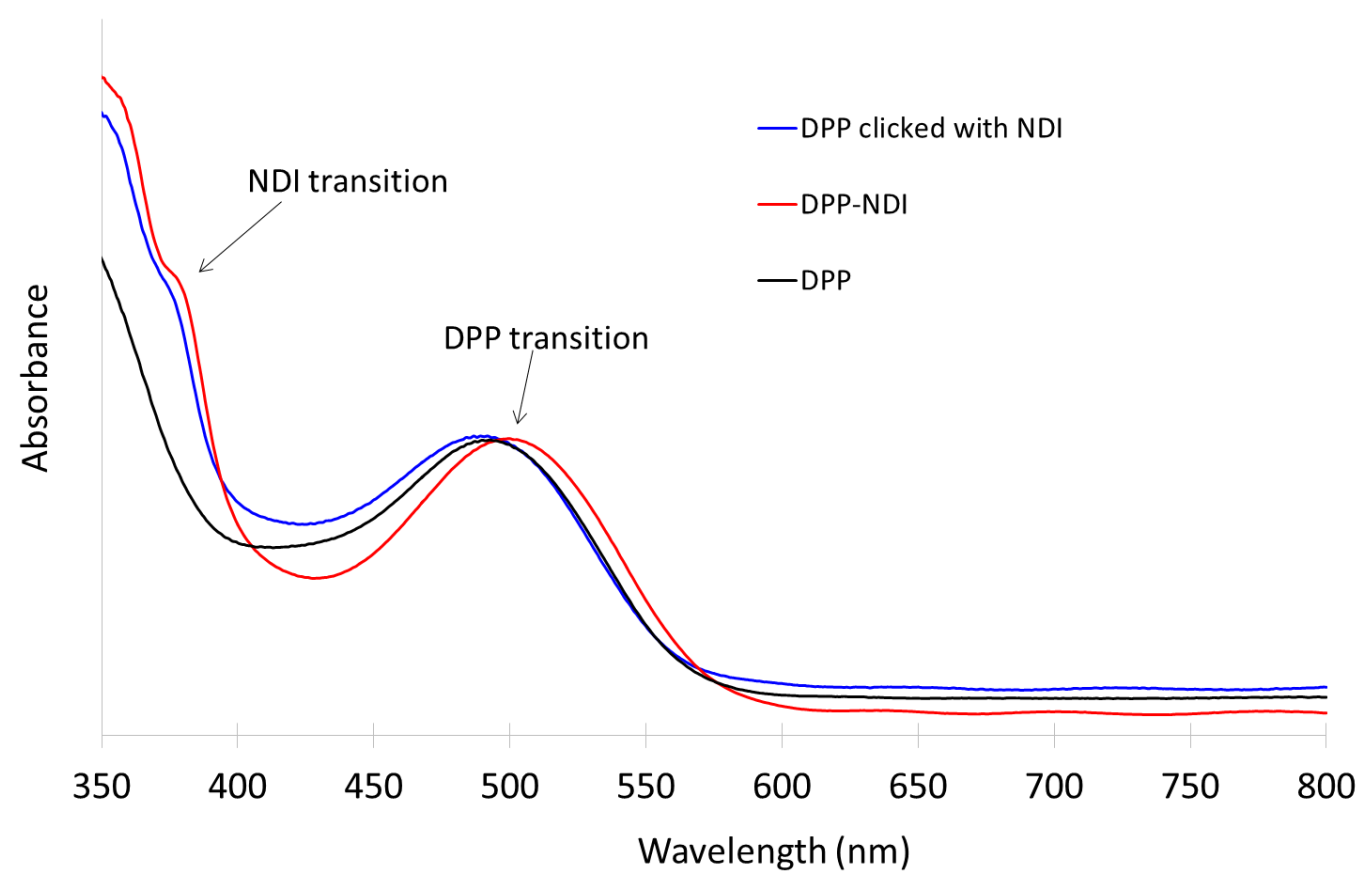

Figure 2. Normalized absorption spectra of $\mathrm{Al}_{2} \mathrm{O}_{3}$ films coated with DPP-NDI (red), DPP before (black) and after click reaction with NDI (blue). The three spectra were normalized on the DPP absorption band.

The spectroscopic and electrochemical data of the compounds are gathered in Table 1 . The determination of the driving forces for the hole injection process into the valence band of NiO and the regeneration reaction of the reduced dye by the redox mediator in the electrolyte were calculated (Table 1). Unsurprisingly, they support that these two reactions are both thermodynamically very favorable and therefore can occur spontaneously.

\section{Photophysical study}

The excited-state dynamics of DPP, DPP-NDI and DPP crosslinked with NDI on NiO were investigated from the femtosecond to the microsecond timescales using electronic transient absorption (TA) spectroscopy to determine the charge-transfer processes taking place upon excitation of the DPP dye at $532 \mathrm{~nm} .{ }^{34,38,39}$ 


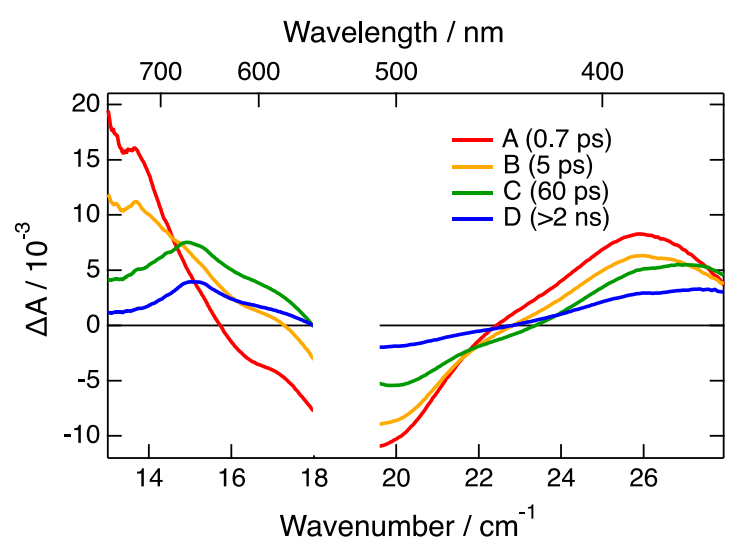

Figure 3. Evolution-associated difference absorption spectra (EADS) obtained upon global analysis of the transient absorption data measured after $532 \mathrm{~nm}$ excitation of DPP on NiO assuming a series of successive exponential steps $(A \rightarrow \ldots \rightarrow D \rightarrow)$

As discussed previously, ${ }^{30}$ the excited-state dynamic of DPP, grafted $\mathrm{NiO}$ with or without crosslinking with CA are essentially the same. Figure 3 shows the evolution-associated difference absorption spectra $(E A D S)^{40,41}$ obtained from a global analysis of the TA data measured with DPP on NiO after $532 \mathrm{~nm}$ excitation assuming a series of successive exponential steps with increasing time constants (see Figure S1 for the data). Directly after excitation of DPP, the TA spectra show positive absorption bands of the singlet excited state of the DPP sub-unit, DPP* $\left(\mathrm{S}_{1}\right)$, at 730 and $390 \mathrm{~nm}$ as well as a negative band between 430 and $620 \mathrm{~nm}$ that is due to both the ground-state bleach around $500 \mathrm{~nm}$ and the stimulated emission at longer wavelengths. The latter decays in a few picoseconds, whereas the $730 \mathrm{~nm}$ band evolves into a band centered around $660 \mathrm{~nm}$ that can be attributed to the radical anion of DPP generated upon hole injection into NiO. ${ }^{42}$ This band losses about half of its maximum intensity with a 60 ps time constant and then decays on a 2-3 ns timescale. An average charge injection time constant of about 2-3 ps can be estimated from the decay of the DPP excited state. 

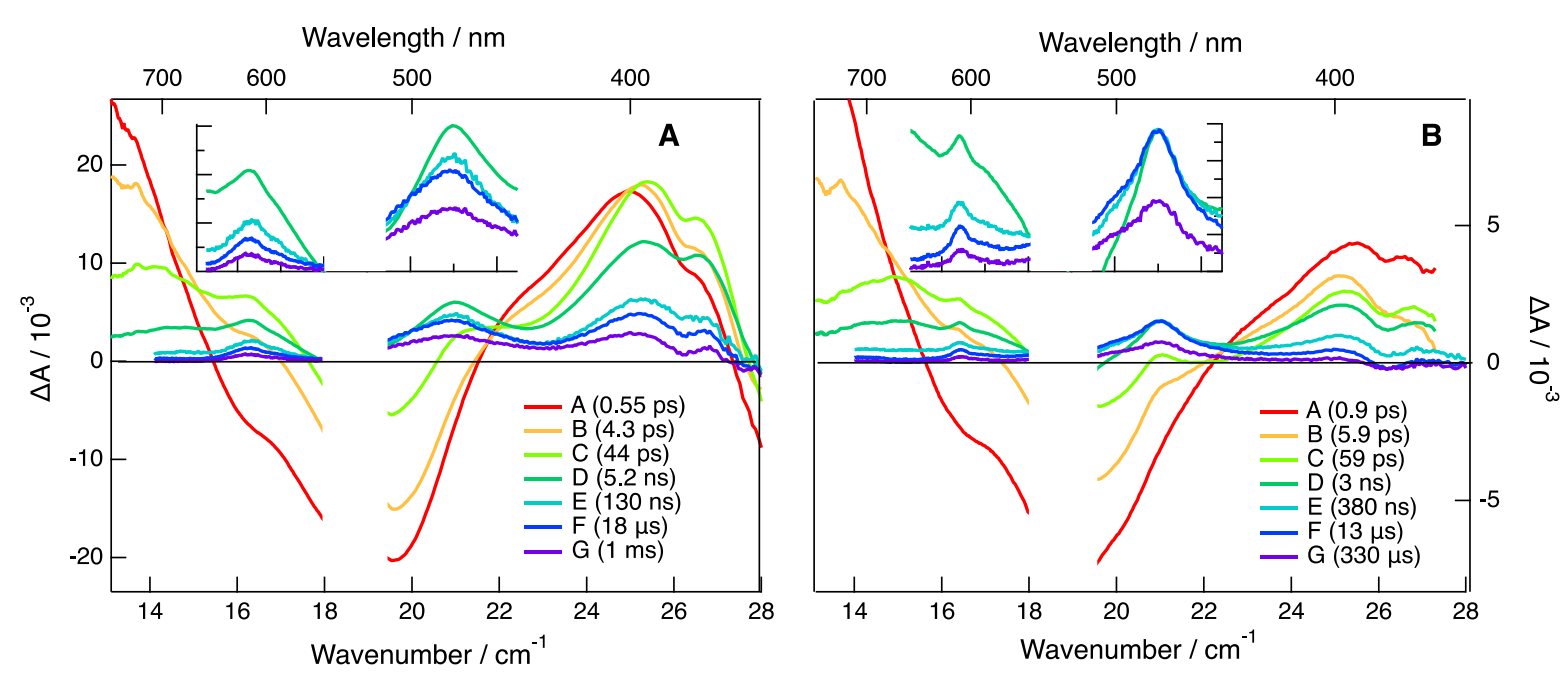

Figure 4. Evolution-associated difference absorption spectra (EADS) obtained upon global analysis of the transient absorption data measured after $532 \mathrm{~nm}$ excitation of A) DPP-NDI and B) DPP crosslinked with NDI on NiO, assuming a series of successive exponential steps $(A \rightarrow \ldots \rightarrow G \rightarrow)$. Inset: zoom-in of EADS D-G. The values in parentheses are the decay times of the corresponding EADS.

Figure 4A shows the EADS obtained from a global analysis of the TA data measured on the femtosecond to microsecond timescales with DPP-NDI grafted on NiO after $532 \mathrm{~nm}$ excitations (see Figure S2-3 for the data). The early spectra are essentially the same as those measured at short time delays with DPP (Figure 3 ) and can, thus, be assigned to the DPP subunit locally excited in the $S_{1}$ state, DPP* $\left(S_{1}\right)$. These features decay on multiple timescales ranging from less than 1 ps to a few ps (EADS A-C). In parallel, distinct maxima appear around 700 and $600 \mathrm{~nm}$. They can be attributed to the radical anion of the DPP and NDI subunits, respectively in agreement with previous works. ${ }^{34,42,43}$ Additionally, the positive band, initially at $400 \mathrm{~nm}$, shifts to shorter wavelength and a dip around 380 $\mathrm{nm}$, that can be assigned to the bleach of the NDI subunit, becomes visible. The overlap of this positive feature with bleaches around $380 \mathrm{~nm}$ and a below $370 \mathrm{~nm}$ makes the assignment of this band difficult. From the time dependence of its relative intensity, it probably contains contributions from both DPP.- and NDI.- after the decay of DPP* $\left(\mathrm{S}_{1}\right) .^{34}$ The attribution of the $700 \mathrm{~nm}$ band in EADS C to DPP.- is supported by the absence of stimulated emission and the relatively strong DPP bleach that hides the $480 \mathrm{~nm}$ band of NDI- ${ }^{-}$. By going from EADS C to D, the decrease of DPP.- band is accompanied by the decay of the DPP bleach and the appearance of NDI-- band at $480 \mathrm{~nm}$. Therefore, hole injection from DPP* $\left(\mathrm{S}_{1}\right)$ to $\mathrm{NiO}$ takes place during the $\mathrm{A} \rightarrow \mathrm{C}(0.55 \mathrm{ps}, 4.3 \mathrm{ps})$ steps, whereas the $C \rightarrow D(44 \mathrm{ps})$ step mostly reflects the shift of the electron from the DPP to the NDI subunit. Due to the inhomogeneity of the dynamics, this shift is also visible in the $B \rightarrow C$ (4.3 ps) step as the rise of the $600 \mathrm{~nm}$ band of $\mathrm{NDI}^{-}$as well as in the slower $\mathrm{D} \rightarrow \mathrm{E}(5.2 \mathrm{~ns})$ step. After about $10 \mathrm{~ns}$, 
the overall shape of the TA spectrum remains mostly constant and is dominated by the NDI-- bands. Their decay can be reproduced using the sum of three exponential functions with $130 \mathrm{~ns}, 18 \mu \mathrm{s}$ and $\sim 1$ ms time constants, giving an average decay time of about $550 \mu \mathrm{s}$.

As illustrated by the EADS depicted in Figure 4B (see Figure S4-5 for the data), the TA spectra measured with DPP crosslinked with NDI on NiO exhibit similar features than those measured with the DPP-NDI dyad (Figure 4A). From the global analysis, it appears that hole injection occurs on similar timescale ( $\mathrm{A} \rightarrow \mathrm{C}$ steps with 0.9 and 5.9 ps time constants) than with the dyad. The presence of DPP.- in EADS C and D is more visible than for the dyad. This can be explained by a slightly slower electron shift to the NDI in the crosslinked system ( 59 ps vs 44 ps), allowing for a larger accumulation of the DPP.- population. This longer lifetime of DPP.- is visible as a slower rise of the NDI-' absorption band at $480 \mathrm{~nm}$ (Figure 5).

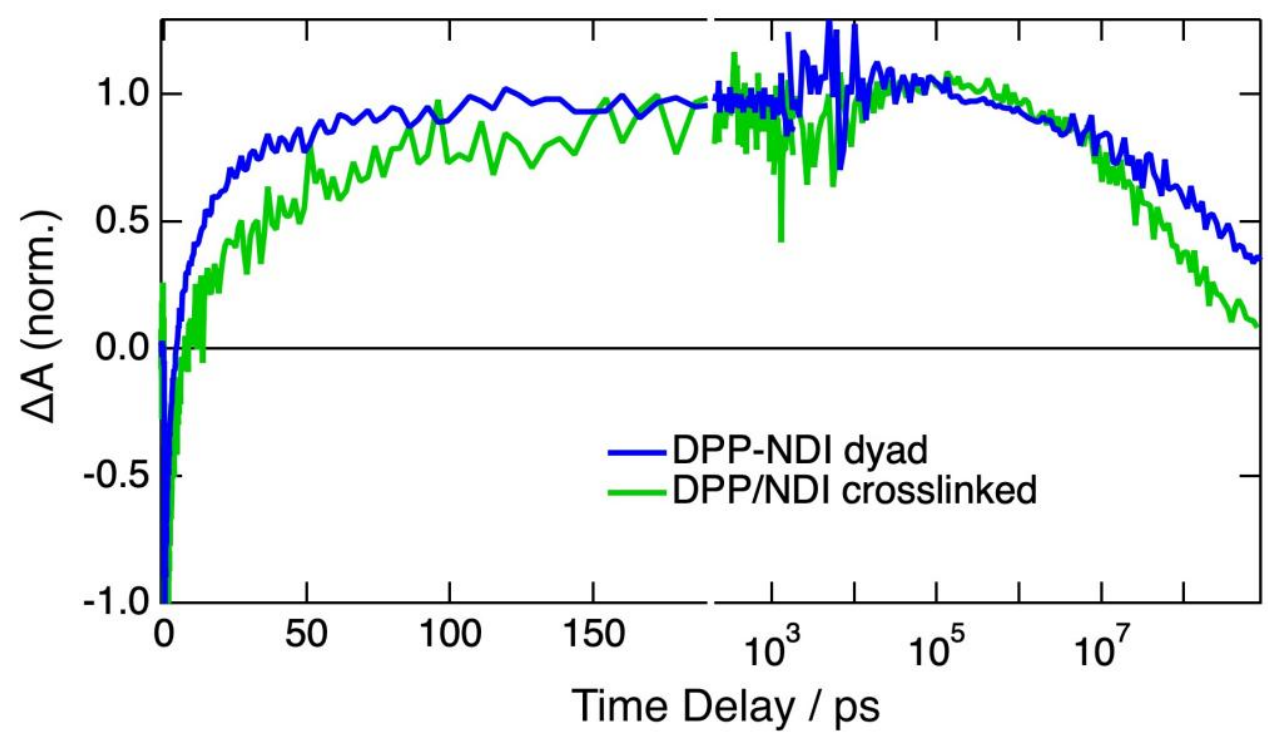

Figure 5. Time profiles of the transient absorption at $480 \mathrm{~nm}$, the maximum of NDI-- absorption band, after excitation of DPP-NDI and DPP crosslinked with NDI on NiO.

After about $10 \mathrm{~ns}$, the TA spectra show only features due to $\mathrm{NDI}^{-}$. The decay of the main NDI-- band at $480 \mathrm{~nm}$ can be reproduced with the sum of two exponential functions with 13 and $330 \mu$ s time constant, corresponding to an average decay time of $170 \mu \mathrm{s}$. This points to a somewhat faster recombination dynamics than for the dyad (Figure 5). This can be explained most reasonably by a shorter mean distance between the NDI and the NiO surface when the latter is linked on the DPP via click chemistry. Figure 6 summarizes the main results of this photophysical study. 


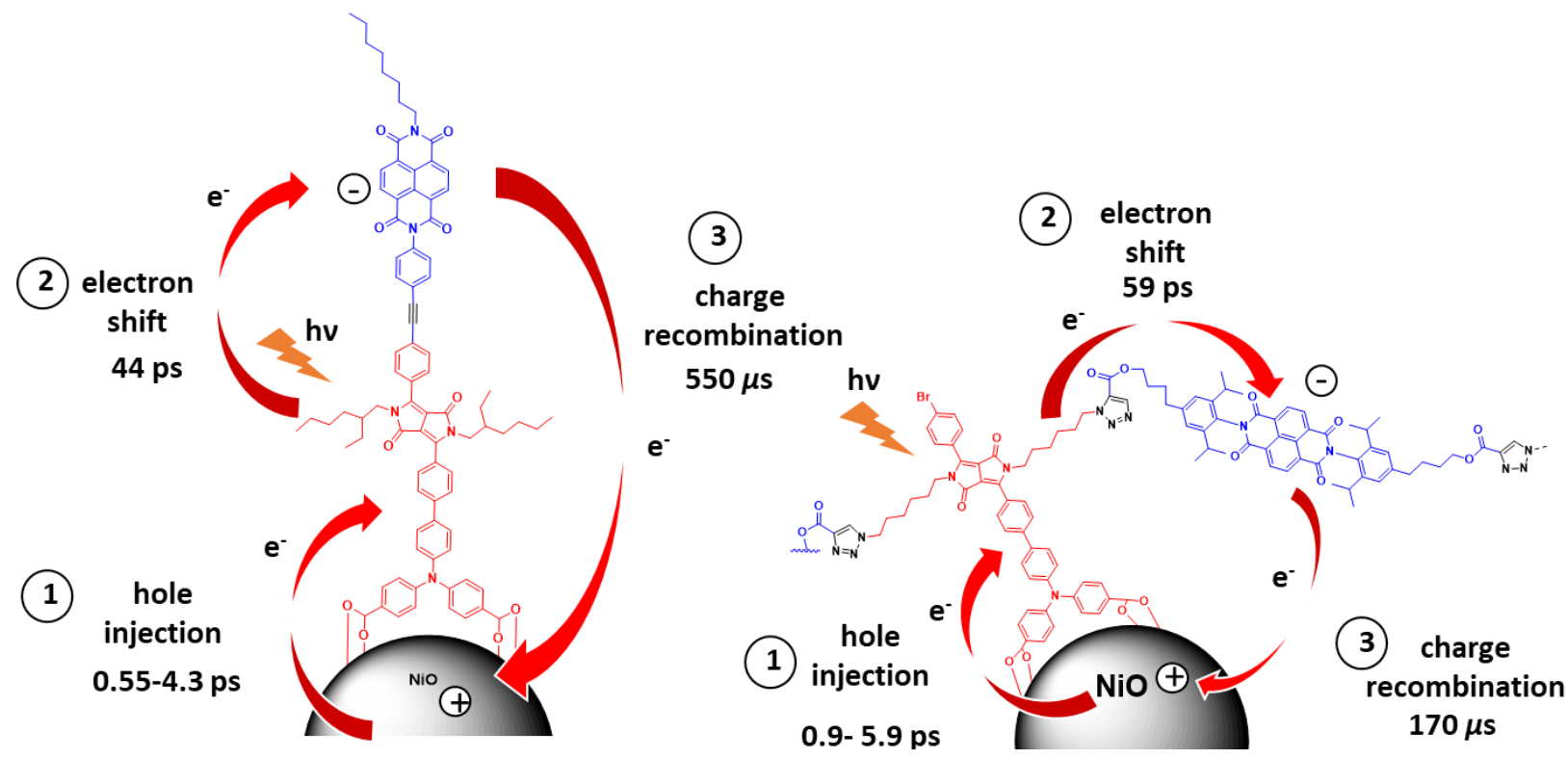

Figure 6. Graphical summary of the main rate constants of the charge transfer processes occurring upon photoexcitation of the DPP dye in the two systems.

\section{Photovoltaic properties}

Solar cells were fabricated on nanocrystalline film of NiO with DPP without and after introduction of NDI by click chemistry and the characteristics of the p-DSSCs were compared to those of the DPP-NDI and DPP cross-linked with the passive tetraalkyne (cross-linking agent : CA Chart). The tris $\left(4,4^{\prime}-\right.$ diterbutyl-2,2'-bipyridine) cobalt complex was used as redox mediator (Figure S6), because this specific redox couple demands a long-lived charge-separated state, enabling thus to indirectly probe the enhancement of the charge-separated state lifetime with NDI. ${ }^{32,44}{ }^{31}$ The metrics from at least three independent solar cells, such as short circuit current density (Jsc), open circuit voltage (Voc), fill factor (ff) and power conversion efficiency (PCE) are gathered in Table 2. Typical current/voltage curves are shown in Figure S7. 
Table 2. Metrics of the solar cells recorded under calibrated AM1.5 $\left(100 \mathrm{~mW} / \mathrm{cm}^{2}\right)$ sunlight simulator.

\begin{tabular}{|c|c|c|c|c|}
\hline & $\begin{array}{c}\mathrm{J}_{\mathrm{SC}} \\
\left(\mathrm{mA} / \mathrm{cm}^{2}\right)\end{array}$ & $\begin{array}{c}\mathrm{V}_{\mathrm{OC}} \\
(\mathrm{mV})\end{array}$ & $\begin{array}{c}\mathrm{FF} \\
(\%)\end{array}$ & $\begin{array}{c}\text { PCE } \\
(\%)\end{array}$ \\
\hline DPP & $0.88 \pm 0.08$ & $133 \pm 6$ & $25 \pm 2$ & $0.023 \pm 0.004$ \\
\hline $\begin{array}{c}\text { DPP crosslinked } \\
\text { with CA }\end{array}$ & $0.87 \pm 0.1$ & $200 \pm 5$ & $28 \pm 1$ & $0.048 \pm 0.008$ \\
\hline $\begin{array}{c}\text { DPP crosslinked } \\
\text { with NDI }\end{array}$ & $1.40 \pm 0.07$ & $254 \pm 8$ & $32 \pm 1$ & $0.10 \pm 0.008$ \\
\hline DPP-NDI & $1.94 \pm 0.05$ & $340 \pm 8$ & $31 \pm 0.7$ & $0.205 \pm 0.003$ \\
\hline
\end{tabular}

The comparison of the characteristics of the solar cells sensitized with the DPP without and after cross-linked with the passive tetraalkyne CA shows that the Jsc was not modified, but the Voc was significantly increased. This is certainly due to the physical barrier brought by the crosslinking agent, which bridges the DPP and most certainly restricts the approach of the redox mediator to the NiO surface.$^{30}$ As a result, the interfacial charge recombinations are reduced and the hole concentration in the $\mathrm{NiO}$ valence band is higher, explaining thus the larger Voc. Interfacial charge recombination reaction is important in p-DSSC and particularly with the one electron outer-sphere redox mediator such as cobalt complexes. ${ }^{32,44}$ The introduction of NDI electron acceptor by click reaction in the film has a real beneficial impact over the passive CA since both Jsc and Voc are raised. These changes are the direct consequence of the longer-lived charge-separated state (hole in NiO and electron on NDI) formed upon electron shift from the reduced DPP to the clicked NDI as demonstrated above by the transient absorption. The comparison of the performances of the solar cells made with the dyad DPP-NDI and the system in which NDI was clicked on DPP shows that the Jsc and Voc are slightly higher with the dyad. However, the superiority of the dyad is not huge (30\%). This result can be explained by the longer-lived charge-separated state achieved with the dyad, probably due to the longer average distance between the NDI and the NiO surface. 


\section{Conclusion}

The present work provides a successful illustration of the post-functionalization of a dye-sensitized photocathode via a copper-free click chemistry by a NDI electron acceptor. The NDI component can be grafted on the DPP dye according to a simple procedure and the electron shift reaction from the reduced DPP and NDI occurs with a good efficiency as confirmed by the photophysical study and the photovoltaic measurements on p-DSSCs. This click reaction is probably compatible with a wide range of molecular components such as catalysts and other dyes to enhance light capture by antenna effect. ${ }^{45}$ This work shows that the chemistry on the electrode via this simple click chemistry strategy has great potential for the straightforward modification of mesoporous metal oxide electrodes, and can represent a significant leap forward in the development of dye-sensitized electrochemical systems.

Acknowledgements: Région des Pays de la Loire is gratefully acknowledged for the financial support of these researches through the project "ClickChemHybrids" via the program LUMOMAT. The authors greatly acknowledge J. Hémez and L. Arzel (AMaCC platform, CEISAM UMR CNRS 6230, University of Nantes) for the mass spectrometry analyses. EV thanks the Swiss National Science Foundation (grant 200020-184607) and the University of Geneva for financial support.

Supporting information available: Synthesis of the NDI, preparation and characterizations of the DSSCs, additional transient absorption spectroscopy spectra, current/voltage characteristics of the

solar cells, and ${ }^{1} \mathrm{H}$ and ${ }^{13} \mathrm{C}$ spectra of the new compounds. The transient absorption data can be downloaded from https://doi.org/10.26037/yareta:3byyprenrzd67d5mja3xndytdy

\section{References:}

(1) Hagfeldt, A.; Boschloo, G.; Sun, L.; Kloo, L.; Pettersson, H. Dye-Sensitized Solar Cells. Chem. Rev. 2010, 110, 6595-6663.

(2) Yu, Z.; Li, F.; Sun, L. Recent advances in dye-sensitized photoelectrochemical cells for solar hydrogen production based on molecular components. Energy Environ. Sci. 2015, 8, 760-775.

(3) Gibson, E. A. Dye-sensitized photocathodes for H2 evolution. Chem. Soc. Rev. 2017, 46, 61946209.

(4) Ashford, D. L.; Gish, M. K.; Vannucci, A. K.; Brennaman, M. K.; Templeton, J. L.; Papanikolas, J. M.; Meyer, T. J. Molecular Chromophore-Catalyst Assemblies for Solar Fuel Applications. Chemical Reviews (Washington, DC, United States) 2015, 115, 13006-13049. 
(5) Yu, M.; Ren, X.; Ma, L.; Wu, Y. Integrating a redox-coupled dye-sensitized photoelectrode into a lithium-oxygen battery for photoassisted charging. Nat. Commun. 2014, 5, ncomms9103.

(6) Nagashima, T.; Ozawa, H.; Suzuki, T.; Nakabayashi, T.; Kanaizuka, K.; Haga, M.-a. Photoresponsive Molecular Memory Films Composed of Sequentially Assembled Heterolayers Containing Ruthenium Complexes. Chem. Eur. J. 2016, 22, 1658-1667.

(7) Nikolaou, V.; Charisiadis, A.; Charalambidis, G.; Coutsolelos, A. G.; Odobel, F. Recent advances and insights in dye-sensitized $\mathrm{NiO}$ photocathodes for photovoltaic devices. J. Mater. Chem. A 2017, 5, 21077-21113.

(8) Dalle, K. E.; Warnan, J.; Leung, J. J.; Reuillard, B.; Karmel, I. S.; Reisner, E. Electro- and Solar-Driven Fuel Synthesis with First Row Transition Metal Complexes. Chemical Reviews (Washington, DC, United States) 2019, 119, 2752-2875.

(9) Matheu, R.; Ertem, M. Z.; Gimbert-Suriñach, C.; Sala, X.; Llobet, A. Seven Coordinated Molecular Ruthenium-Water Oxidation Catalysts: A Coordination Chemistry Journey. Chemical Reviews (Washington, DC, United States) 2019, 119, 3453-3471.

(10) Binder, W. H.; Sachsenhofer, R. 'Click' Chemistry in Polymer and Materials Science. Macromolecular Rapid Commun. 2007, 28, 15-54.

(11) Meldal, M.; Tornøe, C. W. Cu-Catalyzed Azide-Alkyne Cycloaddition. Chem. Rev. 2008, 108, 2952-3015.

(12) Lee, J. K.; Chi, Y. S.; Choi, I. S. Reactivity of Acetylenyl-Terminated Self-Assembled Monolayers on Gold: Triazole Formation. Langmuir 2004, 20, 3844-3847.

(13) Lummerstorfer, T.; Hoffmann, H. Click Chemistry on Surfaces: 1,3-Dipolar Cycloaddition Reactions of Azide-Terminated Monolayers on Silica. J. Phys. Chem. B 2004, 108, 3963-3966.

(14) White, M. A.; Johnson, J. A.; Koberstein, J. T.; Turro, N. J. Toward the Syntheses of Universal Ligands for Metal Oxide Surfaces: Controlling Surface Functionality through Click Chemistry. J. Am. Chem. Soc. 2006, 128, 11356-11357.

(15) Wu, L.; Eberhart, M.; Shan, B.; Nayak, A.; Brennaman, M. K.; Miller, A. J. M.; Shao, J.; Meyer, T. J. Stable Molecular Surface Modification of Nanostructured, Mesoporous Metal Oxide Photoanodes by Silane and Click Chemistry. ACS Appl. Mater. Interfaces 2019, 11, 4560-4567.

(16) Bishop, L. M.; Yeager, J. C.; Chen, X.; Wheeler, J. N.; Torelli, M. D.; Benson, M. C.; Burke, S. D.; Pedersen, J. A.; Hamers, R. J. A Citric Acid-Derived Ligand for Modular Functionalization of Metal Oxide Surfaces via "Click" Chemistry. Langmuir 2012, 28, 1322-1329.

(17) Shah, S.; Benson, M. C.; Bishop, L. M.; Huhn, A. M.; Ruther, R. E.; Yeager, J. C.; Tan, Y.; Louis, K. M.; Hamers, R. J. Chemically assembled heterojunctions of SnO2 nanorods with TiO2 nanoparticles via "click" chemistry. J. Mater. Chem. 2012, 22, 11561-11567.

(18) Cao, Y.; Galoppini, E.; Reyes, P. I.; Lu, Y. Functionalization of Nanostructured ZnO Films by Copper-Free Click Reaction. Langmuir 2013, 29, 7768-7775.

(19) Palomaki, P. K. B.; Dinolfo, P. H. A Versatile Molecular Layer-by-Layer Thin Film Fabrication Technique Utilizing Copper(I)-Catalyzed Azide-Alkyne Cycloaddition. Langmuir 2010, 26, 9677-9685.

(20) Topka, M. R.; Dinolfo, P. H. Synthesis, Characterization, and Fluorescence Properties of Mixed Molecular Multilayer Films of BODIPY and Zn(II) Tetraphenylporphyrins. ACS Appl. Mater. Interfaces 2015, 7, 8053-8060.

(21) Pati, P. B.; Zhang, L.; Philippe, B.; Fernández-Terán, R.; Ahmadi, S.; Tian, L.; Rensmo, H.; Hammarström, L.; Tian, H. Insights into the Mechanism of a Covalently-Linked Organic DyeCobaloxime Catalyst System for Dye Sensitized Solar Fuel Devices. ChemSusChem 2017, 10, 24802495.

(22) Sahara, G.; Kumagai, H.; Maeda, K.; Kaeffer, N.; Artero, V.; Higashi, M.; Abe, R.; Ishitani, O. Photoelectrochemical Reduction of $\mathrm{CO} 2$ Coupled to Water Oxidation Using a Photocathode with a $\mathrm{Ru}(\mathrm{II})-\mathrm{Re}$ (I) Complex Photocatalyst and a CoOx/TaON Photoanode. J. Am. Chem. Soc. 2016, 138, 14152-14158.

(23) Kaeffer, N.; Massin, J.; Lebrun, C.; Renault, O.; Chavarot-Kerlidou, M.; Artero, V. Covalent Design for Dye-Sensitized H2-Evolving Photocathodes Based on a Cobalt Diimine-Dioxime Catalyst. J. Am. Chem. Soc. 2016, 138, 12308-12311. 
(24) Ashford, D. L.; Lapides, A. M.; Vannucci, A. K.; Hanson, K.; Torelli, D. A.; Harrison, D. P.; Templeton, J. L.; Meyer, T. J. Water Oxidation by an Electropolymerized Catalyst on Derivatized Mesoporous Metal Oxide Electrodes. J. Am. Chem. Soc. 2014, 136, 6578-6581.

(25) Lapides, A. M.; Ashford, D. L.; Hanson, K.; Torelli, D. A.; Templeton, J. L.; Meyer, T. J. Stabilization of a Ruthenium(II) Polypyridyl Dye on Nanocrystalline TiO2 by an Electropolymerized Overlayer. J. Am. Chem. Soc. 2013, 135, 15450-15458.

(26) Wu, L.; Brennaman, M. K.; Nayak, A.; Eberhart, M.; Miller, A. J. M.; Meyer, T. J. Stabilization of Ruthenium(II) Polypyridyl Chromophores on Mesoporous TiO2 Electrodes: Surface Reductive Electropolymerization and Silane Chemistry. ACS Central Sci. 2019, 5, 506-514.

(27) Hanson, K.; Torelli, D. A.; Vannucci, A. K.; Brennaman, M. K.; Luo, H.; Alibabaei, L.; Song, W.; Ashford, D. L.; Norris, M. R.; Glasson, C. R. K., et al. Self-Assembled Bilayer Films of Ruthenium(II)/Polypyridyl Complexes through Layer-by-Layer Deposition on Nanostructured Metal Oxides. Angew. Chem. Int. Ed. 2012, 51, 12782-12785.

(28) Materna, K. L.; Lalaoui, N.; Laureanti, J. A.; Walsh, A. P.; Rimgard, B. P.; Lomoth, R.; Thapper, A.; Ott, S.; Shaw, W. J.; Tian, H., et al. Using Surface Amide Couplings to Assemble Photocathodes for Solar Fuel Production Applications. ACS Appl. Mater. Interfaces 2020, 12, 4501-4509.

(29) Materna, K. L.; Beiler, A. M.; Thapper, A.; Ott, S.; Tian, H.; Hammarstroem, L. Understanding the Performance of NiO Photocathodes with Alkyl-Derivatized Cobalt Catalysts and a Push-Pull Dye. ACS Appl. Mater. Interfaces 2020, 12, 31372-31381.

(30) Bentounsi, Y.; Seintis, K.; Ameline, D.; Diring, S.; Provost, D.; Blart, E.; Pellegrin, Y.; Cossement, D.; Vauthey, E.; Odobel, F. Chemistry on the electrodes: post-functionalization and stability enhancement of anchored dyes on mesoporous metal oxide photoelectrochemical cells with copperfree Huisgen cycloaddition reaction. J. Mater. Chem. A 2020, 25, 12633-12640.

(31) Gibson, E. A.; Smeigh, A. L.; Pleux, L. L.; Fortage, J.; Boschloo, G.; Blart, E.; Pellegrin, Y.; Odobel, F.; Hagfeldt, A.; Hammarström, L. A p-Type NiO-based Dye-Sensitized Solar Cell with a Voc of 0.35 V. Angew. Chem. Int. Ed. 2009, 48, 4402-4405.

(32) Odobel, F.; Pellegrin, Y.; Gibson, E. A.; Hagfeldt, A.; Smeigh, A. L.; Hammarström, L. Recent advances and future directions to optimize the performances of p-type dye-sensitized solar cells. Coord. Chem. Rev. 2012, 256, 2414-2423.

(33) Morandeira, A.; Fortage, J.; Edvinsson, T.; Le Pleux, L.; Blart, E.; Boschloo, G.; Hagfeldt, A.; Hammarström, L.; Odobel, F. Improved Photon-to-Current Conversion Efficiency with a Nanoporous p-Type NiO Electrode by the Use of a Sensitizer-Acceptor Dyad. J. Phys. Chem. C 2008, 112, 17211728.

(34) Farré, Y.; Zhang, L.; Pellegrin, Y.; Planchat, A.; Blart, E.; Boujtita, M.; Hammarström, L.; Jacquemin, D.; Odobel, F. Second Generation of Diketopyrrolopyrrole Dyes for NiO-Based DyeSensitized Solar Cells. J. Phys. Chem. C 2016, 120, 7923-7940.

(35) Tian, D.; Zhang, H.-Z.; Zhang, D.-S.; Chang, Z.; Han, J.; Gao, X.-P.; Bu, X.-H. Li-ion storage and gas adsorption properties of porous polyimides (PIs). RSC Advances 2014, 4, 7506-7510.

(36) Wood, C. J.; Summers, G. H.; Clark, C. A.; Kaeffer, N.; Braeutigam, M.; Carbone, L. R.; D'Amario, L.; Fan, K.; Farre, Y.; Narbey, S., et al. A comprehensive comparison of dye-sensitized NiO photocathodes for solar energy conversion. Phys. Chem. Chem. Phys. 2016, 18, 10727-10738.

(37) Renaud, A.; Chavillon, B.; Cario, L.; Pleux, L. L.; Szuwarski, N.; Pellegrin, Y.; Blart, E.; Gautron, E.; Odobel, F.; Jobic, S. Origin of the Black Color of NiO Used as Photocathode in p-Type Dye-Sensitized Solar Cells. J. Phys. Chem. C 2013, 117, 22478-22483.

(38) Aster, A.; Licari, G.; Zinna, F.; Brun, E.; Kumpulainen, T.; Tajkhorshid, E.; Lacour, J.; Vauthey, E. Tuning symmetry breaking charge separation in perylene bichromophores by conformational control. Chem. Sci. 2019, 10, 10629-10639.

(39) Lang, B.; Mosquera-Vazquez, S.; Lovy, D.; Sherin, P.; Markovic, V.; Vauthey, E. Broadband Ultraviolet-Visible Transient Absorption Spectroscopy in the Nanosecond to Microsecond Time Domain with Sub-Nanosecond Time Resolution. Rev. Sci. Instrum. 2013, 84, 073107-8.

(40) van Stokkum, I. H. M.; Larsen, D. S.; van Grondelle, R. Global and Target Analysis of TimeResolved Spectra. Biochim. Biophys. Acta, Bioenerg. 2004, 1657, 82-104. 
(41) Beckwith, J. S.; Rumble, C. A.; Vauthey, E. Data analysis in transient electronic spectroscopy - an experimentalist's view. Int. Rev. Phys. Chem. 2020, 39, 135-216.

(42) Kim, T.; Kim, W.; Vakuliuk, O.; Gryko, D. T.; Kim, D. Two-Step Charge Separation Passing Through the Partial Charge-Transfer State in a Molecular Dyad. J. Am. Chem. Soc. 2020, 142, 1564-1573.

(43) Gosztola, D.; Niemczik, M. P.; Svec, W.; Lukas, A. S.; Wasielewski, M. R. Excited Doublet States of Electrochemically Generated Aromatic Imide and Diimide Radical Anions. J. Phys. Chem. A 2000, 104, 6545-6551.

(44) Gibson, E. A.; Smeigh, A. L.; Le Pleux, L.; Hammarström, L.; Odobel, F.; Boschloo, G.; Hagfeldt, A. Cobalt Polypyridyl-Based Electrolytes for p-Type Dye-Sensitized Solar Cells. J. Phys. Chem. C 2011, 115, 9772-9779.

(45) Odobel, F.; Pellegrin, Y.; Warnan, J. Bio-inspired artificial light-harvesting antennas to enhance solar energy capture in dye-sensitized solar cells. Energy Environ. Sci. 2013, 6, 2041-2052. 


\section{Click chemistry on NiO photocathode to post-functionalize a diketopyrrolopyrrole sensitizer by naphthalene diimide electron acceptor}

Yousra Bentounsi, ${ }^{a}$ Konstantinos Seintis, ${ }^{b}$ Stéphane Diring, ${ }^{a}$ Eric Vauthey ${ }^{*}{ }^{b}$ Fabrice Odobel ${ }^{* a}$

${ }^{a}$ Université de Nantes, CNRS, CEISAM UMR 6230, F-44000 Nantes, France. E-mail: Fabrice.Odobel@univ-nantes.fr

Department of Physical Chemistry, University of Geneva, 30 Quai Ernest-Ansermet, CH-1211 Geneva, Switzerland.E-mail: Eric.Vauthey@unige.ch
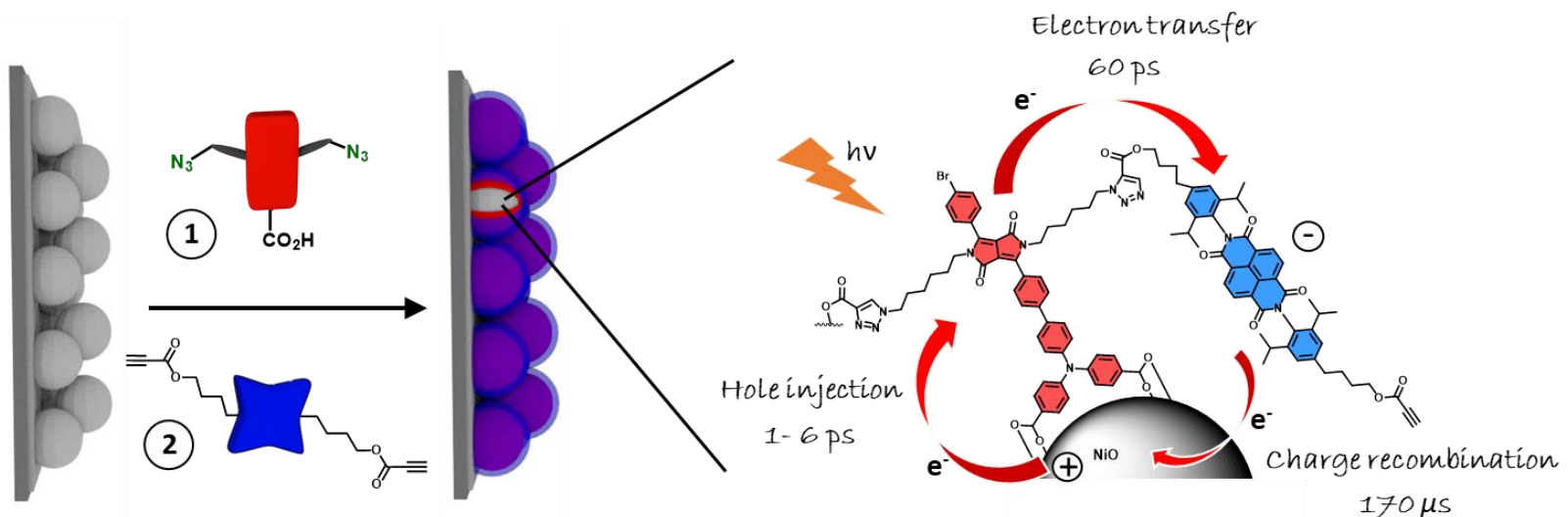